\title{
Conjunction study of plasmapause location using ground-based magnetometers, IMAGE-EUV, and Kaguya-TEX data
}

\author{
Y. Obana, ${ }^{1,2}$ G. Murakami, ${ }^{1}$ I. Yoshikawa, ${ }^{1}$ I. R. Mann, ${ }^{3}$ P. J. Chi, ${ }^{4}$ and M. B. Moldwin ${ }^{4,5}$
}

Received 29 July 2009; revised 26 November 2009; accepted 10 December 2009; published 18 June 2010.

[1] A statistical study comparing the plasmapause location determined using extreme ultraviolet (EUV) and cross-phase measurements was performed over 50 days in May-July 2000 and 1 day in May 2008. In EUV images the plasmapause location was estimated using the sharp gradient in the brightness of $30.4 \mathrm{~nm} \mathrm{He}{ }^{+}$emission. We have taken EUV images obtained by the IMAGE and the Kaguya satellites, which were operated in a solar maximum and minimum periods, respectively. In the ground-based cross-phase measurement, the plasmapause was defined as a steep drop of mass density in its radial profile. Mass density was inferred from the eigenfrequency of field line resonances in the ULF band $(\sim 1-1000 \mathrm{mHz})$, which was deduced from geomagnetic field data using cross-phase analysis. The two measurements of the plasmapause have been compared in a same meridian at the same time and very good agreement was found in 18 of 19 events. Our result clearly indicates that the $\mathrm{He}^{+}$and mass density plasmapause are usually detected at the same place with the error range of $\pm 0.4 R_{E}$. In only one event, the $\mathrm{He}^{+}$and the mass density defined plasmapauses were not colocated. This event may be due to the difference of refilling time between $\mathrm{He}^{+}$and other dominant species.

Citation: Obana, Y., G. Murakami, I. Yoshikawa, I. R. Mann, P. J. Chi, and M. B. Moldwin (2010), Conjunction study of plasmapause location using ground-based magnetometers, IMAGE-EUV, and Kaguya-TEX data, J. Geophys. Res., 115, A06208, doi:10.1029/2009JA014704.

\section{Introduction}

[2] The plasmasphere is a doughnut-shaped region filled with cold plasma of ionospheric origin. The plasmapause, the outer boundary of the plasmasphere that is often observed as a radially steep decline in plasma density, moves in response to the geomagnetic activity [Chappell et al., 1970]. It is well recognized that the plasmapause in steady state can be interpreted as a separatrix between closed and open convection trajectories [Nishida, 1966]. Inside the plasmapause, plasma on magnetic flux tubes rotates at around $80-95 \%$ of corotation [e.g., Sandel et al., 2003; Grew et al., 2007; Galvan et al., 2010], and thus escaping ionospheric plasma can fill toward a "saturated" state. If conditions are quiet and steady for a long period, the plasmasphere can expand beyond L-shell of $\sim 8$. During active times, enhanced magnetic convection leads to erosion of the outer plasmasphere and the plasmapause moves inward. The location of the relocated plasmapause is generally controlled

\footnotetext{
${ }^{1}$ Faculty of Science, University of Tokyo, Tokyo, Japan.

${ }^{2}$ Department of Engineering Science, Osaka Electro-Communication University, Neyagawa, Japan.

${ }^{3}$ Department of Physics, University of Alberta, Edmonton, Alberta, Canada.

${ }^{4}$ Institute of Geophysics and Planetary Physics, University of California, Los Angeles, California, USA.

${ }^{5}$ Department of Atmospheric, Oceanic and Space Sciences, University of Michigan, Ann Arbor, Michigan, USA.
}

Copyright 2010 by the American Geophysical Union. 0148-0227/10/2009JA014704 by the strength of convection. It sometimes reaches to L-shell of $\sim 2-3$, but often shows azimuthal structures [e.g., O'Brien and Moldwin, 2003; Sandel et al., 2003].

[3] In the quasi-stationary picture, the separatrix of the open and closed regions is assumed to coincide with the plasmapause, but in reality this is rare, due to the unsteady and spatially structured convection. The open-closed separatrix does not coincide with the plasmapause during and after storms. The displacement of the boundaries induces erosion and refilling of the plasmasphere [Grebowsky et al., 1970].

[4] Refilling rates of the plasmaspheric plasma vary depending on L-shell, season, solar activity, and ion species. For example, the inverse dependence of $\mathrm{H}^{+}$refilling rate on solar activity is well known [Rasmussen et al., 1993; Su et al., 2001], whereas simulations [Krall et al., 2008] predict that $\mathrm{He}^{+}$refilling rate increases with solar activity. $M . H$. Denton et al. [2002] argued that the $\mathrm{He}^{+}$ion can refill much quicker than the $\mathrm{O}^{+}$and $\mathrm{H}^{+}$ions due to the rapid photoionization of neutral helium. Ion composition in the plasmasphere is also not stable [e.g., M. H. Denton et al., 2002; Berube et al., 2005]. The dominant plasmaspheric ion species is $\mathrm{H}^{+}$, whose number density in the plasmasphere is $\sim 1000 \mathrm{~cm}^{-3}$, roughly $80 \%$ of the total ion number density on average. The next dominant species are usually $\mathrm{He}^{+}$and $\mathrm{O}^{+}$, although, their population can change dramatically. The observed $\mathrm{He}^{+} / \mathrm{H}^{+}$number density ratio varies from 0.01 to 0.05 [e.g., Taylor et al., 1965; Horwitz et al., 1984; Craven et al., 1997; Goldstein et al., 2003]. Horwitz et al. [1984], Fraser et al. [2005], and Berube et al. [2005] sug- 


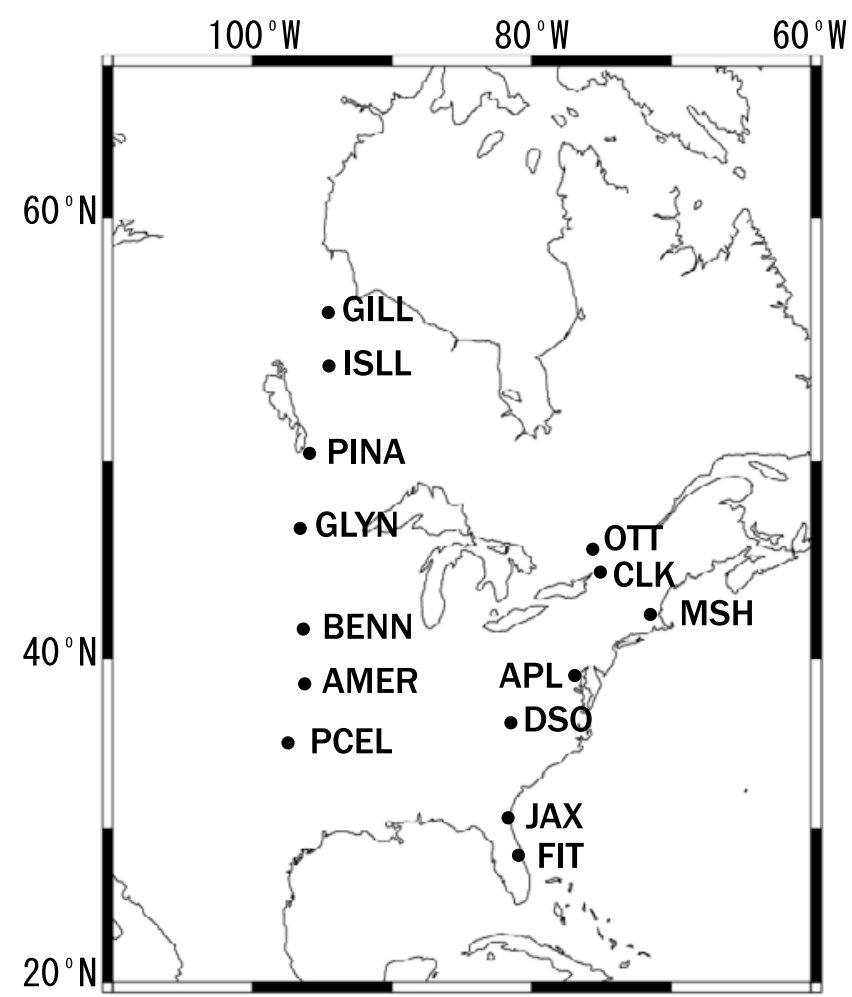

Figure 1. Map showing locations of the ground-based magnetometers used in this study.

gested a torus of $\mathrm{O}^{+}$and $\mathrm{O}^{++}$ions in the vicinity of the newly eroded plasmapause during and following plasmaspheric erosion periods. These results motivate this study. Does the plasmapause location differ among plasma species, especially during times of active depletion and refilling?

[5] In order to address this issue, we compare plasmapause locations detected from two different measurements. The first technique involves measurements of magnetospheric field line resonances. Gradient or cross-phase analysis [Baransky et al., 1989; Waters et al., 1991] from closely spaced ground magnetometers yields the eigenfrequency of magnetic field lines, providing information on the plasma mass density near the equatorial plane. Data from an extended meridional array of ground magnetometers therefore allow the radial density distribution [Dent et al., 2006] and its temporal variation [e.g., Chi et al., 2000; Takahashi et al., 2006; Obana et al., 2009] to be remotely monitored. Menk et al. [2004] explored use of cross-phase analysis to obtain mass density and plasmapause location. They suggested the spatial and temporal resolution in the range $0.15-0.4 R_{E}$ and 20-60 min, respectively, and that the plasmapause can be clearly identified under disturbed conditions.

[6] The most comprehensive measurement of the plasmapause is imaging from outside the plasmasphere using extreme ultraviolet (EUV) light resonantly scattered from $\mathrm{He}^{+}$or $\mathrm{O}^{+}$ions [e.g., Burch et al., 2001; Yoshikawa et al., 2001, 2003]. The EUV camera on board the Image for Magnetosphere-to-Aurora Global Exploration (IMAGE) satellite mapped the distribution of $\mathrm{He}^{+}$ions from a polar orbit with an $8 R_{E}$ apogee. The observation period is 2000 2005, mainly during solar maximum. The Japanese lunar satellite Kaguya is now carrying out the observation of the Earth's plasmasphere during solar minimum [Yoshikawa et al., 2008]. The Telescope of Extreme Ultraviolet (TEX) on the Kaguya satellite has detected terrestrial $\mathrm{He}^{+}$and $\mathrm{O}^{+}$ emissions from lunar orbit. The key technology was developed in the 1990s using sounding rocket experiments [Yamazaki et al., 2002; Yoshikawa et al., 1997]. The Kaguya was launched on 14 September 2007 and maneuvered to be dropped on the Moon on 11 June 2009.

[7] As mentioned above, the dominant plasmaspheric ion species is $\mathrm{H}^{+}$; however, it does not have a resonance wavelength in the EUV band. This is why the EUV measurements target $30.4 \mathrm{~nm}$ or $83.4 \mathrm{~nm}$, which are the resonance wavelengths of $\mathrm{He}^{+}$and $\mathrm{O}^{+}$.

[8] Goldstein et al. [2003] compared the plasmapause location as identified via the Radio Plasma Imager (RPI) and EUV analysis over 1 month and found a very good correlation between the two techniques. To minimize the effect of the time lag, which fundamentally exists between the RPI and EUV measurements, Goldstein et al. [2003] took the average of RPI plasmapause locations observed before and after the EUV measurement. Dent et al. [2006] performed a conjunction study comparing plasmapause locations seen by ground-based magnetometers (using cross-phase), RPI, and EUV. They used simultaneous RPI and cross-phase measurements, whereas EUV had time lag from the others.

[9] In this study, we compared the simultaneous observation of the plasmapause in the same meridian using EUV images and cross-phase analyzed magnetic data. This "ideal" comparison allow us to clarify whether the difference between the measurements determined plasmapause location was attributed to temporal or spatial variation of the plasmapause. This comparison was applied for both solar maximum and minimum using the IMAGE-EUV and Kaguya-TEX measurements.

\section{Instrumentation}

[10] In this section we introduce the instrumentation by showing three case studies.

\subsection{Event on 13 June 2000}

\subsubsection{Ground-Based Magnetometers}

[11] The ground-based magnetometer data presented in this paper are from four arrays in the American sector: the CARISMA (Canadian Array for Realtime Investigations of Magnetic Activity), the CANMOS (Canadian Magnetic Observatory System), the MEASURE (Magnetometers along the Eastern Atlantic Seaboard for Undergraduate Research and Education), and the McMAC (Mid-continent Magnetoseismic Chain). Station locations are shown and described in Figure 1 and Table 1. Field line resonances (FLRs) can be detected from ground magnetometer data focusing on the variation in amplitude and phase as a function of frequency and latitude [Hughes and Southwood, 1976]. In particular, the "gradient method" [Baransky et al., 1989] and "cross-phase method" [Waters et al., 1991] compare amplitude and phase spectra from latitudinally separated ground-based magnetometer pairs to produce an estimate of the local eigenfrequency of the field line whose foot point lies approximately midway between the two sta- 
Table 1. Location of Ground-Based Magnetometer Stations

\begin{tabular}{|c|c|c|c|c|c|c|}
\hline Network & $\begin{array}{l}\text { Station } \\
\text { Code }\end{array}$ & $\begin{array}{c}\text { Geographic } \\
\text { Latitude }\end{array}$ & $\begin{array}{l}\text { Geographic } \\
\text { Longitude }\end{array}$ & $\begin{array}{c}\text { Corrected } \\
\text { Geomagnetic } \\
\text { Latitude }\end{array}$ & $\begin{array}{c}\text { Corrected } \\
\text { Geomagnetic } \\
\text { Longitude }\end{array}$ & L-Value \\
\hline \multirow[t]{3}{*}{ CARISMA } & GILL & $56.4^{\circ} \mathrm{N}$ & $94.6^{\circ} \mathrm{W}$ & $66.0^{\circ}$ & $332.8^{\circ}$ & $6.1 R_{E}$ \\
\hline & ISLL & $53.9^{\circ} \mathrm{N}$ & $94.7^{\circ} \mathrm{W}$ & $63.6^{\circ}$ & $333.1^{\circ}$ & $5.1 R_{E}$ \\
\hline & PINA & $50.2^{\circ} \mathrm{N}$ & $96.0^{\circ} \mathrm{W}$ & $59.9^{\circ}$ & $331.5^{\circ}$ & $4.0 R_{E}$ \\
\hline CANMOS & OTT & $45.4^{\circ} \mathrm{N}$ & $75.6^{\circ} \mathrm{W}$ & $55.9^{\circ}$ & $1.15^{\circ}$ & $3.2 R_{E}$ \\
\hline \multirow[t]{6}{*}{ MEASURE } & CLK & $44.7^{\circ} \mathrm{N}$ & $75.0^{\circ} \mathrm{W}$ & $55.4^{\circ}$ & $2.14^{\circ}$ & $3.1 R_{E}$ \\
\hline & $\mathrm{MSH}$ & $42.6^{\circ} \mathrm{N}$ & $71.5^{\circ} \mathrm{W}$ & $52.9^{\circ}$ & $6.87^{\circ}$ & $2.8 R_{E}$ \\
\hline & APL & $39.2^{\circ} \mathrm{N}$ & $76.9^{\circ} \mathrm{W}$ & $50.0^{\circ}$ & $358.7^{\circ}$ & $2.4 R_{E}$ \\
\hline & DSO & $36.3^{\circ} \mathrm{N}$ & $81.4^{\circ} \mathrm{W}$ & $47.6^{\circ}$ & $352.1^{\circ}$ & $2.2 R_{E}$ \\
\hline & JAX & $30.4^{\circ} \mathrm{N}$ & $81.6^{\circ} \mathrm{W}$ & $41.8^{\circ}$ & $351.4^{\circ}$ & $1.8 R_{E}$ \\
\hline & FIT & $28.1^{\circ} \mathrm{N}$ & $81.0^{\circ} \mathrm{W}$ & $39.6^{\circ}$ & $352.1^{\circ}$ & $1.7 R_{E}$ \\
\hline \multirow[t]{4}{*}{ McMAC } & GLYN & $46.9^{\circ} \mathrm{N}$ & $96.5^{\circ} \mathrm{W}$ & $56.8^{\circ}$ & $331.4^{\circ}$ & $3.3 R_{E}$ \\
\hline & BENN & $41.4^{\circ} \mathrm{N}$ & $96.2^{\circ} \mathrm{W}$ & $51.4^{\circ}$ & $332.2^{\circ}$ & $2.6 R_{E}$ \\
\hline & AMER & $38.5^{\circ} \mathrm{N}$ & $96.3^{\circ} \mathrm{W}$ & $48.5^{\circ}$ & $332.2^{\circ}$ & $2.3 R_{E}$ \\
\hline & PCEL & $35.0^{\circ} \mathrm{N}$ & $97.4^{\circ} \mathrm{W}$ & $44.8^{\circ}$ & $330.9^{\circ}$ & $2.0 R_{E}$ \\
\hline
\end{tabular}

tions. The station pairs employed for the analysis are shown in Table 2.

[12] The plasma mass density corresponding to the deduced eigenfrequency can be calculated using the approximation describing the relationship between the fundamental toroidal eigenperiod and mass density suggested by Vellante and Förster [2006] as their equation (8). Here we assume a dipole magnetic field and a plasma mass density which follows radial power law $\rho=\rho_{0} r^{-\mathrm{m}}$. The $\rho_{0}$ is the plasma mass density in the equatorial plane, $r$ is the geocentric distance along the field line, and $m$ is the mass density index, respectively. In the past, many authors used $m=3-4$ as the typical choice regardless of the L-value. This choice mostly comes from past electron density observations using whistler observations [e.g., Carpenter and Smith, 1964]. Recent in situ studies of the field-aligned variation of electron density have found $m=0-1$ in the plasmasphere [Goldstein et al., 2001; R. E. Denton et al., $2002 \mathrm{a}, 2002 \mathrm{~b}$ ] while in the plasmatrough larger values of $m$ (from 1.7 to 3) have been found [Goldstein et al., 2001; R. E. Denton et al., 2002a, 2002b]. Menk et al. [1999] used harmonics of FLR frequencies and found $m$ is typically $\sim 3$ but shows considerable temporal variation in the range from 1 to 6 . In this study, we have used $m$ to be 3 regardless L-shell, local time, and magnetic activity. According to
Menk et al. [1999], a variation in $m$ from 3 to 6 or from 1 to 3 at $\mathrm{L}=2.8$ causes a change in inferred plasma mass density of only $\pm 2 \%$. Therefore a constant value of $m$ of 3 would be valid at least for the purpose of detection of plasmapause location.

[13] Figure 2b shows an L-value profile of plasma mass density at 15 UT ( 0900-1000 MLT) on 13 June 2000 in the American meridian. Open circles indicate inferred mass density using cross-phase analysis of available geomagnetic data, which are from ISLL-PINA $(\mathrm{L}=4.5)$, OTT-CLK $(\mathrm{L}=$ 3.1), CLK-APL ( $\mathrm{L}=2.7)$, APL-DSO $(\mathrm{L}=2.3)$, DSO-JAX $(\mathrm{L}=1.9)$, and JAX-FIT $(\mathrm{L}=1.7)$ pairs. Horizontal error bars indicate the L-values of the pair of stations. Vertical error bars indicate range of uncertainty of the inferred mass density associated with determining the field line resonance frequency from the cross-phase peak and the unity crossing of the interstation power ratio [Obana et al., 2009]. A decreasing curve in Figure $2 \mathrm{~b}$ is given to guide the eye. It indicates an L-value profile of the mass density in the saturated plasmasphere predicted by Carpenter and Anderson's [1992] model for electron density. The modeled electron density was converted into mass density with the assumption of the ion loading to be 2 . The mass density at $\mathrm{L}<3$ obtained by the cross-phase analysis is more than $2700 \mathrm{amu} \mathrm{cm}{ }^{-3}$ and high enough to be judged inside of the plasmasphere. It

Table 2. Station Pairs and Location of Their Midpoints Applied for Cross-Phase Analysis

\begin{tabular}{lccccc}
\hline Station Code & $\begin{array}{c}\text { Geographic } \\
\text { Latitude }\end{array}$ & $\begin{array}{c}\text { Geographic } \\
\text { Longitude }\end{array}$ & $\begin{array}{c}\text { Corrected } \\
\text { Geomagnetic } \\
\text { Latitude }\end{array}$ & $\begin{array}{c}\text { Corrected } \\
\text { Geomagnetic } \\
\text { Longitude }\end{array}$ & L-Value \\
\hline GILL-ISLL & $55.1^{\circ} \mathrm{N}$ & $94.7^{\circ} \mathrm{W}$ & $64.9^{\circ}$ & $333.1^{\circ}$ & $5.6 R_{E}$ \\
ISLL-PINA & $52.0^{\circ} \mathrm{N}$ & $95.4^{\circ} \mathrm{W}$ & $61.9^{\circ}$ & $332.4^{\circ}$ & $4.5 R_{E}$ \\
OTT-CLK & $45.1^{\circ} \mathrm{N}$ & $75.3^{\circ} \mathrm{W}$ & $55.5^{\circ}$ & $1.6^{\circ}$ & $3.1 R_{E}$ \\
OTT-MSH & $44.5^{\circ} \mathrm{N}$ & $73.5^{\circ} \mathrm{W}$ & $54.8^{\circ}$ & $5.0^{\circ}$ & $3.0 R_{E}$ \\
CLK-APL & $41.9^{\circ} \mathrm{N}$ & $75.9^{\circ} \mathrm{W}$ & $52.6^{\circ}$ & $0.3^{\circ}$ & $2.7 R_{E}$ \\
CLK-DSO & $40.5^{\circ} \mathrm{N}$ & $78.2^{\circ} \mathrm{W}$ & $51.4^{\circ}$ & $356.9^{\circ}$ & $2.6 R_{E}$ \\
MSH-DSO & $39.4^{\circ} \mathrm{N}$ & $76.4^{\circ} \mathrm{W}$ & $50.2^{\circ}$ & $359.3^{\circ}$ & $2.4 R_{E}$ \\
APL-DSO & $37.7^{\circ} \mathrm{N}$ & $79.1^{\circ} \mathrm{W}$ & $48.7^{\circ}$ & $355.3^{\circ}$ & $2.3 R_{E}$ \\
APL-JAX & $34.8^{\circ} \mathrm{N}$ & $79.2^{\circ} \mathrm{W}$ & $45.9^{\circ}$ & $355.0^{\circ}$ & $2.1 R_{E}$ \\
DSO-JAX & $33.3^{\circ} \mathrm{N}$ & $81.5^{\circ} \mathrm{W}$ & $44.5^{\circ}$ & $351.7^{\circ}$ & $1.9 R_{E}$ \\
JAX-FIT & $29.2^{\circ} \mathrm{N}$ & $81.3^{\circ} \mathrm{W}$ & $40.5^{\circ}$ & $351.7^{\circ}$ & $1.7 R_{E}$ \\
PINA-GLYN & $48.5^{\circ} \mathrm{N}$ & $96.2^{\circ} \mathrm{W}$ & $58.4^{\circ}$ & $331.5^{\circ}$ & $3.7 R_{E}$ \\
GLYN-BENN & $4.1^{\circ} \mathrm{N}$ & $96.3^{\circ} \mathrm{W}$ & $54.1^{\circ}$ & $331.8^{\circ}$ & $2.9 R_{E}$ \\
BENN-AMER & $39.9^{\circ} \mathrm{N}$ & $96.2^{\circ} \mathrm{W}$ & $49.9^{\circ}$ & $332.2^{\circ}$ & $2.4 R_{E}$ \\
AMER-PCEL & $36.8^{\circ} \mathrm{N}$ & $96.9^{\circ} \mathrm{W}$ & $46.7^{\circ}$ & $331.5^{\circ}$ & $2.1 R_{E}$ \\
\hline
\end{tabular}


(a)

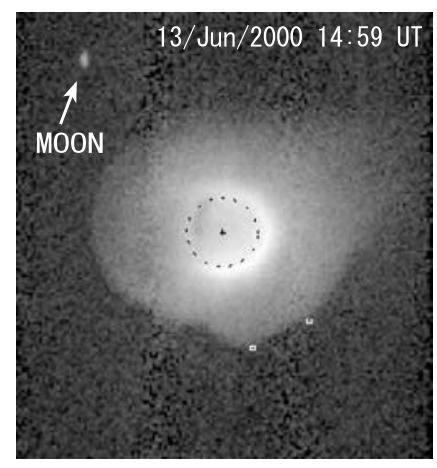

(b)

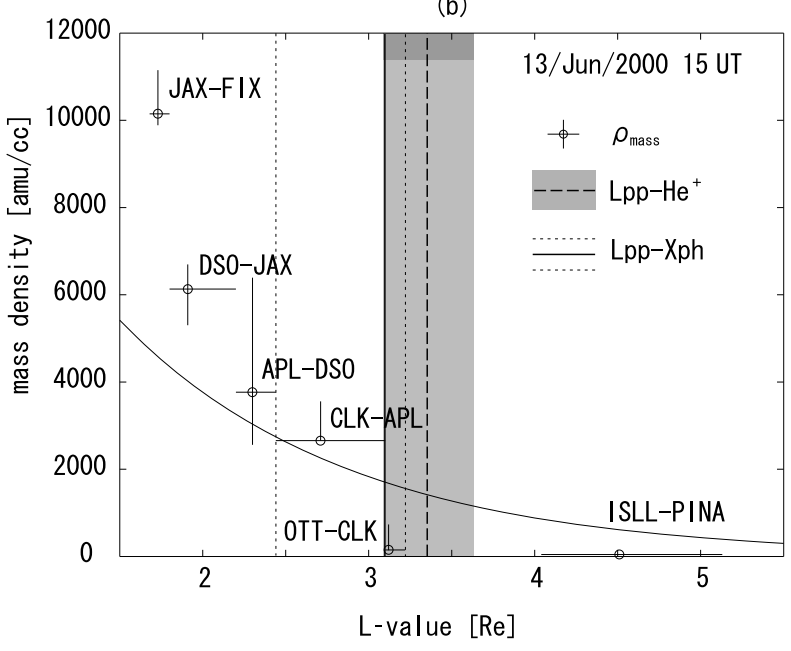

Figure 2. (a) Image of the $\mathrm{He}^{+}$plasmasphere taken by the IMAGE-EUV at 1500 UT on 13 June 2000. The $\mathrm{He}^{+}$ portion of the plasmasphere is shown as the bright haze surrounding the Earth. The " $\mathrm{He}^{+}$edge" plasmapause can be defined at $\mathrm{L}=3.3$ and 3.4 in the $330^{\circ}$ and $360^{\circ}$ magnetic longitude meridians, respectively. (b) L-value profile of plasma mass density inferred from the fundamental frequency of the field line resonances (FLRs). The vertical solid and the dashed lines indicate Lpp-Xph and Lpp- $\mathrm{He}^{+}$, respectively. In this case, they show good agreement.

suddenly drops down to $\sim 150$ amu $\mathrm{cm}^{-3}$ at $\mathrm{L}=3.1$. The plasmapause very likely is located near the sharp drop of the mass density observed at the station pairs of CLK-APL and OTT-CLK. If a cross-phase reversal or zero cross-phase [Waters, 2000; Milling et al., 2001; Abe et al., 2006; Kale et al., 2007] are found, they can be used to monitor the exact position of the plasmapause, but we could not identify such signatures in this case. We do not know whether the plasmapause is located inside one of the two station pairs or straddles them. We estimated the plasmapause at the mass density drop around CLK with an error range between APL and OTT as shown by a solid and two dotted vertical lines in Figure 2b.

\subsubsection{IMAGE-EUV}

[14] At this time, the IMAGE satellite was near apogee and the EUV imager on board the satellite looked down to the equatorial plane and provided a perspective view of the global plasmasphere as shown in Figure 2a. The imager detects EUV light at $30.4 \mathrm{~nm}$, which is resonantly scattered by the $\mathrm{He}^{+}$ions in the plasmasphere. The image has spatial and temporal resolutions of $\sim 0.1 R_{E}$ and $\sim 10 \mathrm{~min}$, respectively, and produces a two-dimensional image showing the column density along the line of sight [e.g., Goldstein et al., 2003]. The Earth's apparent size and location are indicated by the black dotted circle in the center of the image. The light haze around the Earth is the $\mathrm{He}^{+}$portion of the plasmasphere, glowing in $30.4 \mathrm{~nm}$ EUV light. The intensity drops sharply around $\mathrm{L}=3-4$ depending on the local time. The intensity edge has so far been assumed as the plasmapause [e.g., Burch et al., 2001; Goldstein et al., 2003]. The two white squares indicate locations of the sharp $\mathrm{He}^{+}$edge manually extracted in the meridians in which the groundbased magnetometers are located. L-values of the magnetometer derived plasmapause locations are 3.3 and 3.4 in the 330 and $360^{\circ}$ magnetic longitude meridians, respectively.

[15] The vertical dashed line and gray shading in Figure $2 b$ indicate the average of the plasmapause location from EUV data $\left(\mathrm{Lpp}-\mathrm{He}^{+}\right)$and its error range. The error range includes the difference of the $\mathrm{Lpp}-\mathrm{He}^{+}$between the two meridians and the uncertainty associated with the subjectivity of manual plasmapause determination. According to Goldstein et al. [2003], subjectivity involved in the manually extracting the $\mathrm{He}^{+}$edge is about $0.2 R_{E}$ and at least $0.4 R_{E}$ for a sharp and diffuse edges, respectively. Because the $\mathrm{He}^{+}$edge is sharp in this case, the uncertainty is estimated to be $0.2 R_{E}$.

[16] The range of $\mathrm{Lpp}-\mathrm{He}^{+}$and the plasmapause location from the cross-phase measurement (Lpp-Xph) overlap, and thus we conclude that the Lpp estimate from the two measurements is consistent in this case.

\subsection{Event on 31 May 2000}

[17] Figure 3 shows a $\mathrm{He}^{+}$image (a) and L-value profile of plasma mass density (b) at 14 UT ( 8-9 MLT) on 31 May 2000. The format of Figure 3 is almost same as Figure 2, but a cross mark in Figure $3 \mathrm{a}$ indicates a point of $\mathrm{L}=2.3$ in the $330^{\circ}$ magnetic longitude meridian. From the EUV image, the plasmapause was found as a slightly diffusive edge at $\mathrm{L}=3.8$ in the $330^{\circ}-360^{\circ}$ magnetic longitude meridian. There is no other rapid change of $\mathrm{He}^{+}$emission in these meridians, whereas the L-value profile of the mass density in Figure $3 \mathrm{~b}$ shows two significant drops. The first drop is shown between the APL-DSO $(\mathrm{L}=2.3)$ and DSOJAX $(\mathrm{L}=1.9)$ pairs. The mass density indicates almost full flux tubes $\left(4100 \mathrm{amu} \mathrm{cm} \mathrm{cm}^{-3}\right)$ at $\mathrm{L}=1.9$, whereas less than half of saturated values $\left(1300 \mathrm{amu} \mathrm{cm} \mathrm{cm}^{-3}\right)$ are found at $\mathrm{L}=$ 2.3. We determined Lpp-Xph around this drop. It is noteworthy that the EUV image does not show any localized structure in the corresponding region. The second drop is shown between ISLL- PINA ( $\mathrm{L}=4.5$ in $330^{\circ}$ meridian) and OTT-CLK ( $\mathrm{L}=3.1$ in $360^{\circ}$ meridian) pairs which overlap with $\mathrm{Lpp}-\mathrm{He}^{+}$. Mass density at the both sides of the drop is less than half of the saturated values, and thus the drop would reflect a density structure in the plasma trough region. Because of the $\sim 30^{\circ}$ difference of magnetic latitude between the two station pairs, we cannot exclude the possibility of azimuthal structure in total mass density. However, there does not seem to be any evidence for this in the $\mathrm{He}^{+}$seen in the EUV images from this local time. 
(a)

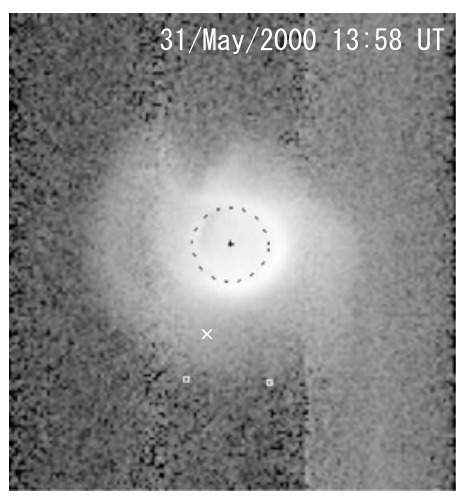

(b)

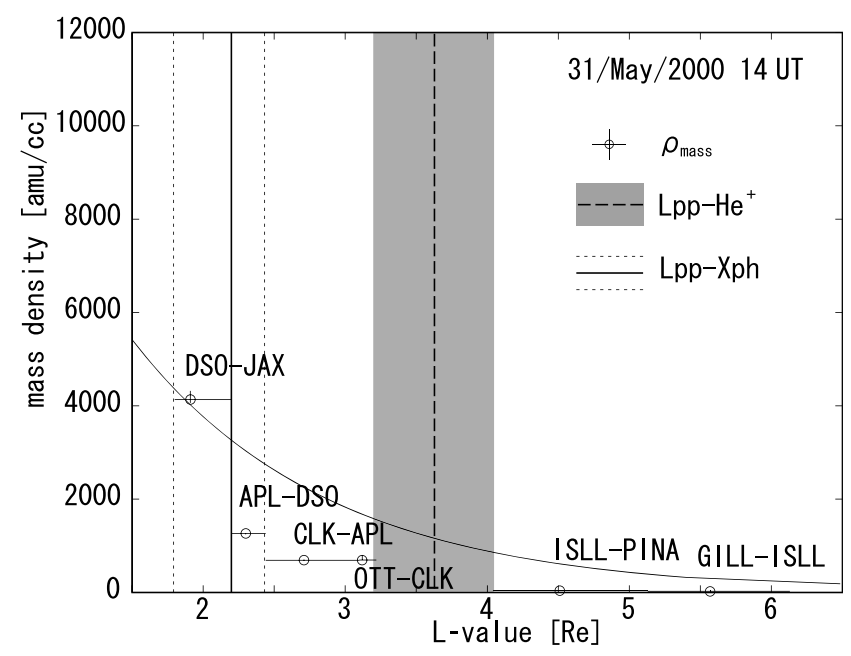

Figure 3. (a) Image of the $\mathrm{He}^{+}$plasmasphere and (b) L-value profile of plasma mass density observed at 1400 UT on 31 May 2000. Format of this figure is same as that of Figure 2. In this case, $\mathrm{Lpp}-\mathrm{He}^{+}$and $\mathrm{Lpp}-\mathrm{Xph}$ are defined at different places.

\subsection{Event on 2 May 2008}

\subsubsection{Kaguya-TEX}

[18] The third case study shows comparison of EUV and cross-phase measurements in a solar minimum period. Figure 4a shows an EUV image of the Earth's plasmasphere at 2100 UT on 2 May 2008 by the TEX on board the Kaguya satellite at the lunar orbit. The image has spatial resolution of $\sim 0.13 R_{E}$. A dashed circle represents the limb of the Earth's disk. A solid and a dotted line and a small circle on the Earth's disk represent the equator line, the dawn boundary, and the subsolar point, respectively. Two curves on the left- and right-hand sides of the Earth show field line of L - 4 at 04 and $16 \mathrm{LT}$, respectively. A white mask covers ghosts made by pinholes on the band-pass filter [Yoshikawa et al., 2010]. This corresponds to the "side view" of the doughnut-shaped plasmasphere. The edge of the $\mathrm{He}^{+}$cloud around the equatorial plane is manually detected at the spot of a white cross. L-value and local time of the detected $\mathrm{He}^{+}$edge are estimated to be $3.5 R_{E}$ and 1400-1600 LT using the coordinates of the field line which passes the spot with smallest L-value. Similar to IMAGEEUV observations, the manual extraction of the $\mathrm{He}^{+}$edge from TEX data also involves subjectivity. We estimate the uncertainly due to the subjectivity in the manual extraction after Goldstein et al.'s [2003] methodology. The $\mathrm{He}^{+}$edge was independently detected by the first three authors of this paper. The difference of the three measurements was less than one pixel. Error range from the uncertainty was estimated to be $\sim 0.2 R_{E}$ from length of diagonal of a pixel.

\subsubsection{Ground-Based Magnetometers}

[19] At the same time, plasma mass density were obtained by cross-phase analysis using geomagnetic data from the CARISMA and McMAC chains as shown in Figure 4b whose format is same as Figures $2 b$ and $3 b$. We can find a mass density drop between PINA-GLYN (L = 3.7) and GLYN-BENN ( $\mathrm{L}=2.9$ ). Additionally, reverse cross-phase signature appeared at PINA-GLYN (not shown) such that the uncertainty of the cross-phase determine plasmapause can be confined to lying between only one station pair in Figure 4 (PINA-GLYN). We hence deduced Lpp-Xph between PINA and GLYN. Location of $\mathrm{He}^{+}$edge and mass density drop show good agreement in this case. This is the first result to identify image of the plasmasphere and the plasmapause in Kaguya-TEX data using other simultaneous observations, and also the first confirmation of coincidence of Lpp- $\mathrm{He}^{+}$and Lpp-Xph in the solar minimum period.

\section{A Statistical Study}

[20] In order to compare $\mathrm{Lpp}-\mathrm{He}^{+}$and $\mathrm{Lpp}-\mathrm{Xph}$, we survey every orbit of the IMAGE satellite during the interval from 23 May to 11 July 2000. The following criteria were employed to select events.

[21] 1. The EUV instrument took clear images of the $\mathrm{He}^{+}$ plasmasphere, especially in a bin of $330^{\circ}-360^{\circ}$ magnetic longitude where the ground-based magnetometers are located.

[22] 2. The IMAGE satellite was at least $6 R_{E}$ far from the Earth's center. Views from such large distance allow global perspectives of the plasmasphere.

[23] 3. Time of day was restricted to 1100-2300 UT when the ground-based magnetic field observatories were on the dayside. Because FLRs are dominant in the dayside magnetosphere, the cross-phase analysis is usually restricted there.

[24] 4. We took at least a $3 \mathrm{~h}$ interval between two events.

[25] This procedure produced 21 events to be extracted. We applied the cross-phase analysis for the 21 events and successfully identify Lpp-Xph in the 18 of them. In addition, we survey Kaguya-TEX data and found one period for conjunction study with cross-phase analyzed magnetic data (shown in Figure 4).

[26] Table 3 shows the event list. Date, UT, Lpp- $\mathrm{He}^{+}$, and Lpp-Xph are shown in the first four columns. The remaining three columns show predicted plasmapause location from three empirical models (details are described in section 4). In 18 of the 19 events $(95 \%)$, the error range of $\mathrm{Lpp}^{-\mathrm{He}^{+}}$(or Lpp-Xph) is included in or at least overlapped with the others. In 12 of the 18 events (67\%), difference between Lpp- $\mathrm{He}^{+}$and Lpp-Xph is less than $0.4 R_{E}$. This is clearly shown in Figure 5, a plot of $\mathrm{Lpp}-\mathrm{He}^{+}$versus $\mathrm{Lpp}-\mathrm{Xph}$. 
(a)

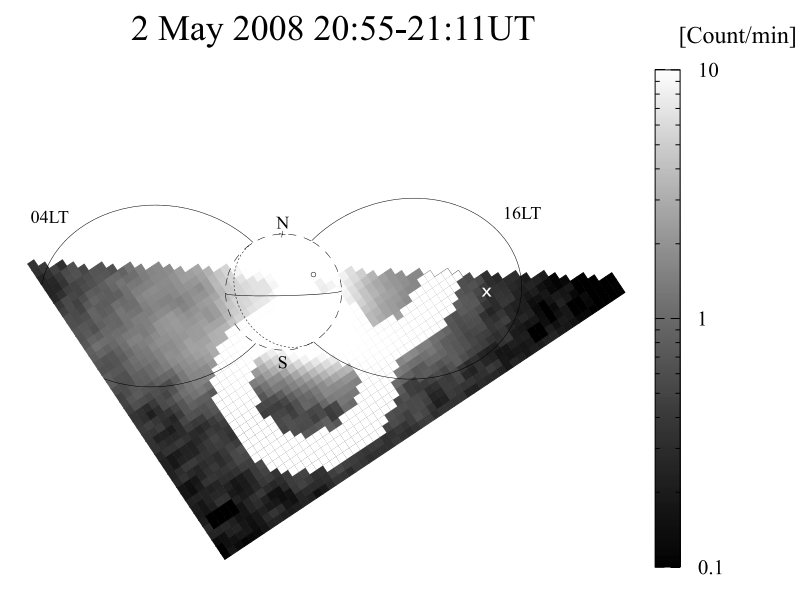

(b)

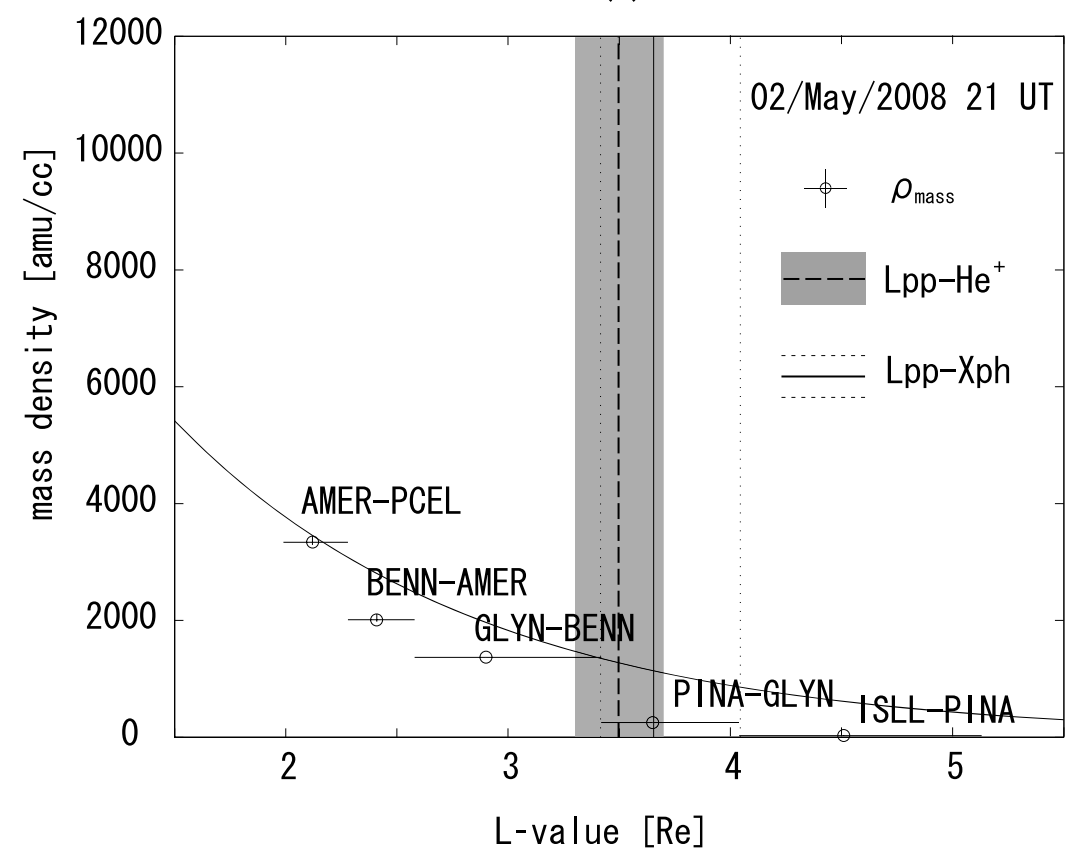

Figure 4. (a) Image of the $\mathrm{He}^{+}$plasmasphere taken by the Kaguya-TEX at $21 \mathrm{UT}$ on 2 May 2009. The "He ${ }^{+}$edge" can be defined at the spot shown by the white cross at L $=3.5$ at $1400 \mathrm{LT}$. (b) L-value profile of plasma mass density observed at 2100 UT on 2 May 2008. Format is same as that of Figure $2 \mathrm{~b}$. In this case, Lpp-He ${ }^{+}$and Lpp-Xph show good agreement.

Circles and triangles indicate the events in which $\mathrm{He}^{+}$edges were obtained from IMAGE-EUV and Kaguya-TEX data, respectively. Horizontal and vertical lines indicate error range of each measurement.

\section{Discussion}

\subsection{Comparison With Models}

[27] Our measurements have been compared with plasmapause locations predicted from three empirical models. The three rightmost columns in Table 3 show plasmapause location estimated using O'Brien and Moldwin's [2003] model with $D s t$ and $K p$ indices and Carpenter and Anderson's
[1992] model with $K p$ index, respectively. The O'Brien and Moldwin [2003] model with Dst index successfully predicted plasmapause location inside of the error range of Lpp-He $\mathrm{H}^{+}$and Lpp-Xph in 11 (58\%) and 12 (63\%) events, respectively. It would suggest that $D s t$ index well represents the strength of the convection electric field which erodes the outer plasmasphere, whereas the two models with $K p$ index well predicted Lpp-Xph (12 events, 63\%) but poorly predicted $\mathrm{Lpp}-\mathrm{He}^{+}$(five to six events, 26-32\%). We can suggest a possibility why the $K p$ models perform poorly to predict $\mathrm{Lpp}-\mathrm{He}^{+}$. There can be a significant azimuthal structure to the plasmapause in the aftermath of a storm [e.g., Moldwin et al., 2003a]. According to O'Brien and 
Table 3. Plasmapause Locations Obtained From Observations and Empirical Models ${ }^{\mathrm{a}}$

\begin{tabular}{lcccccc}
\hline & & & & \multicolumn{3}{c}{ Lpp_models } \\
\cline { 4 - 7 } Date & Time & Lpp_He $^{+}$ & Lpp_Xph & Dst & $K p$ & CA92 \\
\hline 23 May 2000 & 1800 & $4.72 \pm 1.11$ & $3.40 \pm 0.64$ & 4.46 & 3.99 & 2.52 \\
31 May 2000 & 1400 & $3.76 \pm 0.47$ & $2.32 \pm 0.12$ & 3.57 & 3.69 & 3.76 \\
07 Jun 2000 & 1500 & $4.43 \pm 0.46$ & $3.57 \pm 0.47$ & 4.17 & 3.37 & 3.30 \\
8 Jun 2000 & 1900 & $2.49 \pm 0.25$ & $2.83 \pm 0.39$ & 3.05 & 2.94 & 2.38 \\
9 Jun 2000 & 1000 & $2.89 \pm 0.31$ & $3.16 \pm 0.10$ & 3.06 & 2.53 & 2.38 \\
9 Jun 2000 & 2200 & $3.35 \pm 0.41$ & $3.57 \pm 0.47$ & 3.58 & 3.21 & 3.30 \\
11 Jun 2000 & 1800 & $2.34 \pm 0.32$ & $2.32 \pm 0.12$ & 3.38 & 3.45 & 3.30 \\
13 Jun 2000 & 1500 & $3.36 \pm 0.27$ & $3.57 \pm 0.47$ & 3.45 & 3.90 & 3.90 \\
14 Jun 2000 & 1600 & $4.48 \pm 0.32$ & $4.12 \pm 1.02$ & 3.68 & 3.64 & 3.44 \\
16 Jun 2000 & 1400 & $4.14 \pm 0.51$ & $3.63 \pm 0.41$ & 3.69 & 3.06 & 3.62 \\
24 Jun 2000 & 1900 & $3.91 \pm 0.21$ & $3.57 \pm 0.47$ & 3.70 & 3.43 & 3.16 \\
26 Jun 2000 & 1400 & $2.89 \pm 0.21$ & $2.71 \pm 0.51$ & 3.20 & 3.24 & 3.16 \\
27 Jun 2000 & 1700 & $2.83 \pm 0.42$ & $2.77 \pm 0.33$ & 3.06 & 3.06 & 2.84 \\
3 Jul 2000 & 1700 & $3.60 \pm 0.67$ & $2.83 \pm 0.39$ & 5.98 & 4.20 & 4.36 \\
5 Jul 2000 & 1300 & $3.25 \pm 0.28$ & $4.07 \pm 0.97$ & 4.54 & 4.21 & 4.08 \\
6 Jul 2000 & 1500 & $4.73 \pm 0.54$ & $5.09 \pm 1.05$ & 4.51 & 4.07 & 4.22 \\
10 Jul 2000 & 1800 & $4.45 \pm 0.40$ & $4.18 \pm 0.96$ & 4.02 & 3.77 & 3.44 \\
11 Jul 2000 & 2300 & $4.42 \pm 1.38$ & $3.24 \pm 0.80$ & 4.35 & 3.72 & 3.16 \\
2 May 2008 & 2100 & $3.50 \pm 0.20$ & $3.73 \pm 0.31$ & 3.75 & 3.64 & 3.44 \\
\hline a Values are & & & & & &
\end{tabular}

${ }^{\mathrm{a}}$ Values are in Earth radii $\left(R_{E}\right)$.

Moldwin [2003], their $K p$ model well described local time structure in the plasmapause, whereas it poorly predicted absolute position of the plasmapause as comparison with the $D s t$ model. The poor prediction of $K p$ model may imply that Lpp_He ${ }^{+}$reflects such azimuthal structure better than Lpp_Xph. It requires further study in the future.

\subsection{Discrepancy Between Lpp-He ${ }^{+}$and Lpp-Xph}

[28] In only one event, 31 May 2000 shown in Figure 3, were $\mathrm{Lpp}-\mathrm{He}^{+}$and $\mathrm{Lpp}-\mathrm{Xph}$ found to be at different places. Did two boundaries really exist at different places in the magnetosphere? Because the two measurements were obtained simultaneously and applied to the same meridians, the effect of temporal and azimuthal variations of the plasmapause location might be expected to be small. Certainly, the distortion of field lines should be carefully examined for potential effects on the inferred cross-phase mass density profile. For example, the plasmapause can be mapped at the wrong place when field lines are distorted, because EUV and cross-phase are remote-sensing techniques and we assumed a dipole field line to map a point on the equatorial plane. Moreover, differential field stretching across a meridian might also skew the inferred location of steep density gradients. To examine this issue, we compared the geometry of field lines using the International Geomagnetic Reference Field (IGRF) and Tsyganenko 1996 (T96 [Tsyganenko and Stern, 1996] models and found less than $5 \%$ of distortion of field lines around $\mathrm{L} \sim 4$ for this event. It is too small to interpret the displacement of $\mathrm{Lpp}-\mathrm{He}^{+}$and Lpp-Xph.

[29] Now we will discuss the lower threshold of sensitivity of EUV imaging. Goldstein et al. [2003] used intercomparison between shallow density gradient measured by the RPI and diffusive edge measured by the EUV camera and determined that the IMAGE-EUV cannot see much below densities corresponding to $40 \pm 10$ electrons $\mathrm{cm}^{-3}$. This threshold density is the same as inferred by Moldwin et al. [2003b], who compared the EUV signal intensity and Magnetospheric Plasma Analyzed (MPA) data from the Los Alamos National Laboratory's (LANL) geosynchronous satellites. If a mass loading is assumed to be 2.5 [e.g., Takahashi et al., 2006], corresponding plasma mass density is $100 \pm 25 \mathrm{amu} \mathrm{cm}^{-3}$. As shown in Figure 3b, the inferred mass density was $700 \mathrm{amu} \mathrm{cm}{ }^{-3}$ and $40 \mathrm{amu} \mathrm{cm}{ }^{-3}$, respectively at just inside (OTT-CLK, L = 3.1) and outside (ISLLPINA, $\mathrm{L}=4.5$ ) of the $\mathrm{Lpp}-\mathrm{He}^{+}$. It cannot be denied that the Lpp- $\mathrm{He}^{+}$was not correctly detected due to instrumental limitations, but the actual $\mathrm{He}^{+}$edge is outside of the $\mathrm{L}$-shall of the OTT-CLK pair.

[30] We conclude that the plasmapause may be actually defined at different places in terms of $\mathrm{He}^{+}$ions and in terms of total plasma mass densities.

\subsection{Mechanisms}

[31] The location of Lpp-Xph and $\mathrm{Lpp}-\mathrm{He}^{+}$at different places may be explained by differences of refilling rates between $\mathrm{He}^{+}$and other dominant species [M. H. Denton et al., 2002]. If the flux tubes at $\mathrm{L}<3.7$ were saturated for $\mathrm{He}^{+}$ions, whereas still refilling for other species, the observed displacement can be qualitatively explained. The interval for this case study (1400 UT on 31 May) is $40 \mathrm{~h}$ after the commencement of recovery of a small magnetic storm (the minimum Dst value was $-54 \mathrm{nT}$ at $2200 \mathrm{UT}$ on 29 May). A previous cross-phase study [Obana et al., 2009] showed that depleted flux tubes at $\mathrm{L}>2.3 R_{E}$ require more than 2 days to refill to the prestorm level. On 31 May, flux tubes would be on the way of refilling for mass density. M. H. Denton et al. [2002] argued that the $\mathrm{He}+$ ion refills very quickly via the rapid photoionization of neutral helium in the $F$ region and the topside ionosphere, whereas the recovery of the $\mathrm{O}+$ and $\mathrm{H}^{+}$ions is less rapid due to the

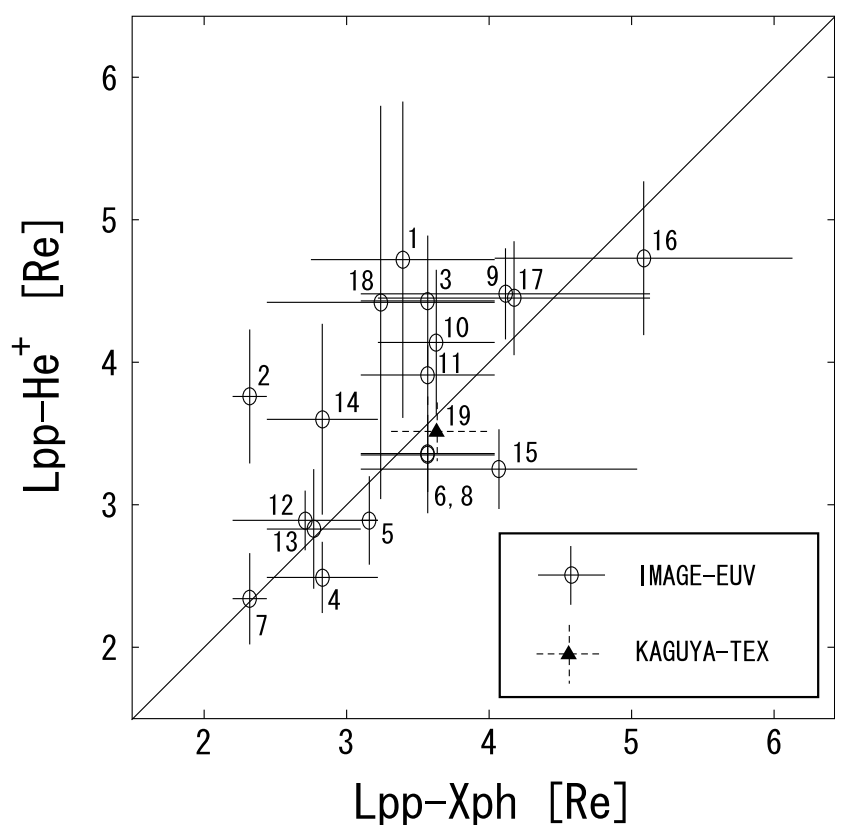

Figure 5. Plot of Lpp-He ${ }^{+}$versus Lpp-Xph. The circles and the triangle indicate events in which IMAGE-EUV and Kaguya-TEX data were used, respectively. In 18 of the 19 events, Lpp-Xph and Lpp-He ${ }^{+}$show good agreement. 
charge exchange reaction between them. A simulation suggested by Krall et al. [2008] showed that refilling is dependent on the supply of ions from the topside of the ionosphere. $\mathrm{He}^{+}$refilling rate generally increase and $\mathrm{H}^{+}$ refilling rates decrease with increasing $F_{10.7}$ index. Their results would encourage our scenario in a solar maximum period.

[32] We next examine two other possible scenarios. The first one is the effect of local concentration of heavy ions. Previous studies [e.g., Horwitz et al., 1984; Berube et al., 2005] suggested heavy ions concentrations near the plasmapause during refilling periods and Fraser et al. [2005] showed mass loading due to heavy ions, especially $\mathrm{O}^{+}$ concentration, can modify radial mass density profile around the plasmapause. However, the effect of mass loading moves Lpp-Xph outward as opposed to our result (Lpp-Xph located inside of $\mathrm{Lpp}-\mathrm{He}^{+}$).

[33] The second scenario is the effect of modulation of the mode of FLR oscillations. In this paper, we have inferred the mass density from FLR eigenfrequency by assuming halfwavelength-mode standing field line oscillations. However, Obana et al. [2008] suggested that cross-phase technique can detect quarter-wavelength modes of standing field line oscillations when the ionospheric Pedersen conductance was strongly asymmetric between both ends of a field line, where the inferred mass density would be overestimated. At 1400 UT on 31 May, both foot points of the field line at L 2 were in the dayside, and thus the Pedersen conductance does not show such strong asymmetry. It would therefore be difficult to generate quarter waves.

\subsection{Ion Composition}

[34] In order to study the $\mathrm{He}^{+}$ion concentration, we studied $\mathrm{He}^{+} /$total plasma mass density ratio at $\mathrm{L}<3.1$ on 31 May $2000 . \mathrm{He}^{+}$number density has been calculated from intensity of EUV signals using Gallaher et al.'s [2005] method shown in their appendix with the $30.4 \mathrm{~nm}$ of solar irradiance obtained from the SOLAR 2000 irradiance model [Tobiska, 2004]. At $\mathrm{L}=1.9$, inside of Lpp-Xph, $\mathrm{He}^{+}$ number density was $100\left(\mathrm{~cm}^{-3}\right)$ which account for $10 \%$ of total mass density, whereas at $\mathrm{L}=2.3,2.7$, and 3.1 , between Lpp-Xph and Lpp- $\mathrm{He}^{+}, \mathrm{He}^{+}$number density was $60 \mathrm{~cm}^{-3}$, $37 \mathrm{~cm}^{-3}$, and $21 \mathrm{~cm}^{-3}$, respectively, which account for $19 \%$, $22 \%$, and $12 \%$, respectively, of total mass density. This clearly shows that $\mathrm{He}^{+}$concentrations between Lpp-Xph and $\mathrm{Lpp}-\mathrm{He}^{+}$are variable.

\section{Conclusions}

[35] We examined the structure of the plasmapause using EUV imaging of and cross-phase analyzed ground-based geomagnetic data. The two measurements give us the opportunity to investigate the plasmapause location in the same meridian at the same time. The EUV imaging data were provided by two satellites and instruments: the IMAGE-EUV and the Kaguya-TEX, which were operated in solar maximum and minimum periods, respectively. This is the first conjunction study of Kaguya-TEX data with other observational data. The plasmapause in EUV images was defined as a steep drop of EUV brightness of $30.4 \mathrm{~nm}$ $\mathrm{He}^{+}$emission. Cross-phase analysis applied to geomagnetic data provided total plasma mass density in the equatorial plane in the magnetosphere. The plasmapause can be identified as a steep drop of plasma mass density in its L-value profile. Reversal and unclearness of cross-phase signature sometimes helped to improve accuracy of the plasmapause location. We successfully defined the plasmapause location from the two measurements and found good general agreement with the error range of $\pm 0.4 R_{E}$ between them in both solar maximum and minimum periods.

[36] In only one event, the EUV $\mathrm{He}^{+}$edge and the crossphase inferred mass density drop were found not to be colocated. For this case, between the two boundaries, the $\mathrm{He}^{+}$concentration was found to increase. This may be interpreted in terms of a larger refilling rate of $\mathrm{He}^{+}$than that of other dominant species, perhaps outside of a recently depleted plasmapause consistent with the modeling of $M$. $H$. Denton et al. [2002]. More work, including more studies during solar minimum, and further and improved modeling are needed.

[37] Acknowledgments. We thank B. R. Sandel for providing IMAGE EUV data. We thank D. Boteler and the CANMOS teams for magnetometer data. CANMOS is operated by the Geological Survey of Canada, part of Natural Resources Canada. The MEASURE and McMac Arrays were supported by grants from the National Science Foundation. CARISMA (www.carisma.ca) is operated and deployed by the University of Alberta and funded by the Canadian Space Agency. CARISMA data were obtained through the Canadian Space Science Data Portal (www.cssdp.ca). We thank the WDC for Geomagnetism, Kyoto for providing Dst index. We also thank NOAA/National Geophysical Data Center (NGDC) for providing $K p$ index.

[38] Zuyin Pu thanks Jerry Goldstein and another reviewer for their assistance in evaluating this paper.

\section{References}

Abe, S., H. Kawano, J. Goldstein, S. Ohtani, S. I. Solovyev, D. G. Baishev, and K. Yumoto (2006), Simultaneous identification of a plasmaspheric plume by a ground magnetometer pair and IMAGE extreme ultraviolet imager, J. Geophys. Res., 111, A11202, doi:10.1029/2006JA011653.

Baransky, L. N., S. P. Belokris, Y. E. Borovkov, M. B. Gokhberg, E. N. Fedorov, and C. A. Green (1989), Restoration of the meridional structure of geomagnetic pulsation fields from gradient measurements, Planet. Space Sci., 37(7), 859-864, doi:10.1016/0032-0633(89)90136-0.

Berube, D., M. B. Moldwin, S. F. Fung, and J. L. Green (2005), A plasmaspheric mass density model and constraints on its heavy ion concentration, J. Geophys. Res., 110, A04212, doi:10.1029/2004JA010684.

Burch, J. L., et al. (2001), Views of Earth's magnetosphere with the Image satellite, Science, 291(5504), 619-624, doi:10.1126/science.291. 5504.619 .

Carpenter, D. L., and R. R. Anderson (1992), An ISEE/Whistler model of equatorial electron-density in the magnetosphere, J. Geophys. Res., 97(A2), 1097-1108, doi:10.1029/91JA01548.

Carpenter, D. L., and R. L. Smith (1964), Whistler measurements of electron density in the magnetosphere, Rev. Geophys., 2(3), 415-441, doi:10.1029/RG002i003p00415.

Chappell, C. R., K. K. Harris, and G. W. Sharp (1970), A study of the influence of magnetic activity on the location of the plasmapause as measured by OGO 5, J. Geophys. Res., 75(1), 50-56, doi:10.1029/JA075i001p00050.

Chi, P. J., C. T. Russell, S. Musman, W. K. Peterson, G. Le, V. Angelopoulos, G. D. Reeves, M. B. Moldwin, and F. K. Chun (2000), Plasmaspheric depletion and refilling associated with the September 25, 1998, magnetic storm observed by ground magnetometers at L = 2, Geophys. Res. Lett., 27(5), 633-636, doi:10.1029/1999GL010722.

Craven, P. D., D. L. Gallagher, and R. H. Comfort (1997), Relative concentration of $\mathrm{He}^{+}$in the inner magnetosphere as observed by the DE 1 retarding ion mass spectrometer, J. Geophys. Res., 102(A2), 2279-2289, doi:10.1029/96JA02176.

Dent, Z. C., I. R. Mann, J. Goldstein, F. W. Menk, and L. G. Ozeke (2006), Plasmaspheric depletion, refilling, and plasmapause dynamics: A coordinated ground-based and IMAGE satellite study, J. Geophys. Res., 111, A03205, doi:10.1029/2005JA011046. 
Denton, M. H., G. J. Bailey, C. R. Wilford, A. S. Rodger, and S. Venkatraman (2002), He+ dominance in the plasmasphere during geomagnetically disturbed periods: 1. Observational results, Ann. Geophys., 20(4), 461-470.

Denton, R. E., J. Goldstein, and J. D. Menietti (2002a), Field line dependence of magnetospheric electron density, Geophys. Res. Lett., 29(24), 2205, doi:10.1029/2002GL015963.

Denton, R. E., J. Goldstein, J. D. Menietti, and S. L. Young (2002b), Magnetospheric electron density model inferred from Polar plasma wave data, J. Geophys. Res., 107(A11), 1386, doi:10.1029/2001JA009136.

Fraser, B. J., J. L. Horwitz, J. A. Slavin, Z. C. Dent, and I. R. Mann (2005), Heavy ion mass loading of the geomagnetic field near the plasmapause and ULF wave implications, Geophys. Res. Lett., 32, L04102, doi:10.1029/2004GL021315.

Gallagher, D. L., M. L. Adrian, and M. W. Liemohn (2005), Origin and evolution of deep plasmaspheric notches, J. Geophys. Res., 110, A09201, doi:10.1029/2004JA010906.

Galvan, D. A., M. B. Moldwin, B. R. Sandel, and G. Crowley (2010), On the causes of plasmaspheric rotation variability: IMAGE EUV observations, J. Geophys. Res., 115, A01214, doi:10.1029/2009JA014321.

Goldstein, J., R. E. Denton, M. K. Hudson, E. G. Miftakhova, S. L. Young, J. D. Menietti, and D. L. Gallagher (2001), Latitudinal density dependence of magnetic field lines inferred from Polar plasma wave data, J. Geophys. Res., 106(A4), 6195-6201, doi:10.1029/2000JA000068.

Goldstein, J., M. Spasojevic, P. H. Reiff, B. R. Sandel, W. T. Forrester, D. L. Gallagher, and B. W. Reinisch (2003), Identifying the plasmapause in image EUV data using IMAGE RPI in situ steep density gradients, J. Geophys. Res., 108(A4), 1147, doi:10.1029/2002JA009475.

Grebowsky, J. M. (1970), Model study of plasmapause motion, J. Geophys. Res., 75, 4329-4333.

Grew, R. S., F. W. Menk, M. A. Clilverd, and B. R. Sandel (2007), Mass and electron densities in the inner magnetosphere during a prolonged disturbed interval, Geophys. Res. Lett., 34, L02108, doi:10.1029/ 2006GL028254

Horwitz, J. L., R. H. Comfort, and C. R. Chappell (1984), Thermal ion composition measurements of the formation of the new outer plasmasphere and double plasmapause during storm recovery phase, Geophys. Res. Lett., 11(8), 701-704, doi:10.1029/GL011i008p00701.

Hughes, W. J., and D. J. Southwood (1976), The screening of micropulsation signals by the atmosphere and ionosphere, J. Geophys. Res., 81, 3234-3240, doi:10.1029/JA081i019p03234.

Kale, Z. C., I. R. Mann, C. L. Waters, J. Goldstein, F. W. Menk, and L. G. Ozeke (2007), Ground magnetometer observation of a cross-phase reversal at a steep plasmapause, J. Geophys. Res., 112, A10222, doi:10.1029/ 2007JA012367.

Krall, J., J. D. Huba, and J. A. Fedder (2008), Simulation of field-aligned $\mathrm{H}^{+}$and $\mathrm{He}^{+}$dynamics during late-stage plasmasphere refilling, Ann. Geophys., 26(6), 1507-1516.

Menk, F. W., D. Orr, M. A. Clilverd, A. J. Smith, C. L. Waters, D. K. Milling, and B. J. Fraser (1999), Monitoring spatial and temporal variations in the dayside plasmasphere using geomagnetic field line resonances, J. Geophys. Res., 104(A9), 19,955-19,969, doi:10.1029/1999JA900205.

Menk, F. W., I. R. Mann, A. J. Smith, C. L. Waters, M. A. Clilverd, and D. K. Milling (2004), Monitoring the plasmapause using geomagnetic field line resonances, J. Geophys. Res., 109, A04216, doi:10.1029/ 2003JA010097.

Milling, D. K., I. R. Mann, and F. W. Menk (2001), Diagnosing the plasmapause with a network of closely spaced ground-based magnetometers, Geophys. Res. Lett., 28(1), 115-118, doi:10.1029/2000GL011935.

Moldwin, M. B., S. Mayerberger, H. K. Rassoul, T. Barnicki, and R. R. Anderson (2003a), Plasmapause response to geomagnetic storms: CRRES results, J. Geophys. Res., 108(A11), 1399, doi:10.1029/2003JA010187.

Moldwin, M. B., B. Sandel, M. Thomsen, and R. Elphic (2003b), Quantifying global plasmaspheric images with in situ observations, Space Sci. Rev., 109, 47-61, doi:10.1023/B:SPAC.0000007512.69979.8f

Nishida, A. (1966), Formation of plasmapause, or magnetospheric plasma knee, by combined action of magnetospheric convection and plasma escape from tail, J. Geophys. Res., 71(23), 5669-5679.

Obana, Y., F. W. Menk, M. D. Sciffer, and C. L. Waters (2008), Quarterwave modes of standing Alfvén waves detected by cross-phase analysis, J. Geophys. Res., 113, A08203, doi:10.1029/2007JA012917.

Obana, Y., F. W. Menk, and I. Yoshikawa (2009), Ion refilling rates for $L=2.3-3.8$ flux tubes, J. Geophys. Res., 115, A03204, doi:10.1029/ 2009JA014191.
O'Brien, T. P., and M. B. Moldwin (2003), Empirical plasmapause models from magnetic indices, Geophys. Res. Lett., 30(4), 1152, doi:10.1029/ 2002GL016007.

Rasmussen, C. E., S. M. Guiter, and S. G. Thomas (1993), A 2-dimensional model of the plasmasphere-Refilling time constants, Planet. Space Sci., 41(1), 35-43, doi:10.1016/0032-0633(93)90015-T.

Sandel, B. R., J. Goldstein, D. L. Gallagher, and M. Spasojević (2003) Extreme ultraviolet imager observations of the structure and dynamics of the plasmasphere, Space Sci. Rev., 109, 25, doi:10.1023/B:SPAC $0000007511.47727 .5 \mathrm{~b}$

Su, Y. J., M. F. Thomsen, J. E. Borovsky, and D. J. Lawrence (2001), A comprehensive survey of plasmasphere refilling at geosynchronous orbit, J. Geophys. Res., 106(A11), 25,615-25,629, doi:10.1029/ 2000JA000441.

Takahashi, K., R. E. Denton, R. R. Anderson, and W. J. Hughes (2006), Mass density inferred from toroidal wave frequencies and its comparison to electron density, J. Geophys. Res., 111, A01201, doi:10.1029/ 2005JA011286.

Taylor, H. A., H. C. Brinton, and C. R. Smith (1965), Positive ion composition in magnetoionosphere obtained from OGO-A satellite, J. Geophys. Res., 70(23), 5769, doi:10.1029/JZ070i023p05769.

Tobiska, W. K. (2004), Solar2000 irradiances for climate change research, aeronomy and space system engineering, Adv. Space Res., 34(8), 17361746.

Tsyganenko, N. A., and D. P. Stern (1996), Modeling the global magnetic field of the large-scale Birkeland current systems, J. Geophys. Res., 101, 27,187-27,198.

Vellante, M., and M. Förster (2006), Inference of the magnetospheric plasma mass density from field line resonances: A test using a plasmasphere model, J. Geophys. Res., 111, A11204, doi:10.1029/ 2005JA011588.

Waters, C. L. (2000), ULF resonance structure in the magnetosphere, in Coordinated Measurements of Magnetospheric Processes, edited by C. T. Russell, Adv. Space Res., 25(7/8), 1541-1558.

Waters, C. L., F. W. Menk, and B. J. Fraser (1991), The resonance structure of low-latitude Pc3 geomagnetic pulsations, Geophys. Res. Lett., 18(12), 2293-2296, doi:10.1029/91GL02550.

Yamazaki, A., S. Tashiro, Y. Nakasaka, I. Yoshikawa, W. Miyake, and M. Nakamura (2002), Sounding-rocket observation of O II 83.4-nm emission over the polar ionosphere, Geophys. Res. Lett., 29(21), 2005 doi:10.1029/2002GL014788.

Yoshikawa, I., M. Nakamura, M. Hirahara, Y. Takizawa, K. Yamashita, H. Kunieda, T. Yamazaki, K. Misaki, and A. Yamaguchi (1997), Observation of He II emission from the plasmasphere by a newly developed EUV telescope on board sounding rocket S-520-19, J. Geophys. Res., 102(A9), 19,897-19,902, doi:10.1029/97JA01530.

Yoshikawa, I., A. Yamazaki, K. Shiomi, K. Yamashita, Y. Takizawa, and M. Nakamura (2001), Loss of plasmaspheric ions during a storm observed by the EUV scanner onboard Planet-B, J. Geophys. Res. 106(A9), 18,911-18,918, doi:10.1029/2001JA900016.

Yoshikawa, I., A. Yamazaki, K. Yamashita, Y. Takizawa, and M. Nakamura (2003), Which is a significant contributor for outside of the plasmapause, an ionospheric filling or a leakage of plasmaspheric materials? Comparison of Heii (304 ̊) images, J. Geophys. Res., 108(A2), 1080 , doi:10.1029/2002JA009578.

Yoshikawa, I., et al. (2008), Telescope of Extreme Ultraviolet (TEX) onboard KAGUYA: Science from the Moon, Earth Planets Space, 60(4), 407-416.

Yoshikawa, I., et al. (2010), Plasmaspheric EUV images seen from lunar orbit: Initial results of the extreme ultraviolet telescope on board the Kaguya spacecraft, J. Geophys. Res., 115, A04217, doi:10.1029/ 2009JA014978.

P. J. Chi and M. B. Moldwin, Institute of Geophysics and Planetary Physics, University of California, Los Angeles, CA 90095, USA.

I. R. Mann, Department of Physics, University of Alberta, Edmonton, AB T6G 2J1, Canada.

G. Murakami, Y. Obana, and I. Yoshikawa, Faculty of Science, University of Tokyo, Tokyo, Japan. (obana@isc.osakac.ac.jp) 